\title{
URBAN TRANSPORT PLANNING AND ENERGY RESOURCES: ELECTRIC VEHICLE ROUTING WITH RELIABLE LINK TRAVEL TIMES
}

\author{
ANTONIO POLIMENI ${ }^{1} \&$ ANTONINO VITETTA ${ }^{2}$ \\ ${ }^{1}$ Department of Enterprise Engineering, "Tor Vergata" University of Rome, Italy \\ ${ }^{2}$ Dipartimento di ingegneria dell'Informazione, delle Infrastrutture e dell'Energia Sostenibile, \\ Università Mediterranea di Reggio Calabria, Italy
}

\begin{abstract}
The rise of new types of vehicles, as the electrical vehicles (EVs), requires defining new models for transport simulation and design, both for freight and for passengers. This paper focuses on freight transport on the land side and it is in the area of the smart city where transport, energy and information and communications technology sectors are considered. This paper focuses on the transport sector and, in particular, the formulation of a vehicle routing problem is considered. The adopted approach considers three aspects: reliable travel time, path generation and best route design for electric vehicles. A possible formulation for a vehicle routing problem with time windows is reported, considering a specific constraint for electric vehicles. The main results obtained in some case studies are reported.

Keywords: electrical vehicles, vehicle routing problem, smart cities.
\end{abstract}

\section{INTRODUCTION}

The freight's planning [1], optimization and management, in recent years, have assumed a relevant role from sea (S) side [2], [3] and land (L) side [4]-[6]. In this paper methods adopted in land side for solving the problem of freight vehicle routing is considered.

The paper can be considered in the area of smart city [7]. In this area, there are three main interconnected sectors of interest: (1) Transport; (2) Energy; and (3) Information and Communications Technology (ICT). This paper is mainly defined in the sector of (1) transport planning. The problem is studied assuming external and fixed scenario for: (2) low emission vehicle in relation to the energy; and (3) technologies adopted in the information and communications areas.

In land (L) side and transport planning sector (1) of the smart city area, the main objective of the method is to design the Transport Freight Services (TFS): it consists in defining the best order of visit and the best route followed by freight vehicles in taking and delivery of freight [8]-[10] and the planning of the best location of the distribution centre [11].

For the method reported in this paper (L., 1., TFS), in the state of the art the following aspects are considered: (a) estimation of reliable link travel time; (b) generation and choice of the best path (assumed as the connection between two points of visit); (c) evaluation and choice of the best route (assumed as joint paths for a ring); d. typology of vehicles; (d) propulsion system adopted for the vehicles. Very often single aspects or combination of two or three of them are considered.

(a) In relation to the estimation of reliable link travel time it could be evaluated adopting three methods:

a.1 traffic assignment, simulating the interaction between transport demand and supply performances [12], [13] or the design of the supply configuration [14];

a.2 real-time system monitoring, assuming the value observed with a monitoring system derived from ICT [15], [16]; 
a.3 reverse assignment, considering data from ICT monitoring system (a.2) and adopting a reverse assignment simulation (a.1) and optimization model [17].

(b) In relation to the generation and choice of the best path the problem is solved simulating two level of choice:

b.1 choice set generation, simulating the choice of paths alternatives perceived by the drivers and the system manager [18]-[21];

b.2 choice from the choice set (b.1), simulating the alternative chosen.

(c) In relation to the evaluation of the best route:

c.1 exact approaches, designing the optimal route in an exact way: [22]-[31];

c.2 heuristic approaches, designing a route more or less near to the optimal with an approximate approach [32]-[40].

(d) In relation to the propulsion system, the electric vehicles can be classified as [41]-[43]:

d.1 pure electric vehicle with only electric propulsion and rechargeable batteries;

d.2 hybrid electric vehicle with mix electric and tradition fuel propulsion; in relation of the grade of hybrid it can be sub-classified in sub-, micro-, mild-, full-hybrid; in relation of the architecture of the two propulsion it can be classified in series-, parallel-, series_parallel-, complex-hybrid;

d.3 extended range electric vehicle considering together d.1, d.2 and improving fuel efficiency.

Category d.1 are plug-in. Category d.2 and d. 3 can or cannot be plug-in.

Note that ICT is included in points a.2 and a3.

In land side, transport planning sector of the smart city area, for design the transport freight services, the innovation of this paper consists in integrating the four (a., b., c., d.) aspects in a whole method. The method is specified considering reliable link travel times and electrical vehicles.

The paper is divided in the following sections: in Section 2 the method adopted is specified; in Section 3 some results and application obtained in literature are reported; in Section 4 some conclusions and further developments are reported.

\section{METHOD}

The method (Fig. 1) is applied to a transport system. The system is modelled by considering two subsystems: supply, represented by a transport network; demand, represented by the travel demand for passengers and freight (Section 2.1).

The data relating to the transport model are used to calculate the link costs to be used in the transport network. This step gives the performances on each link of the network as output data (Section 2.2).

Given the performances on the links, methods for paths search are applied; it considers the generation of the choice set and choice of routes. This step gives the best path from each pair of visit points as output data (Section 2.3).

At the last level the vehicle routing optimization procedure are applied. This step gives the best route (vehicle routing) for vehicles as output data (Section 2.4).

\subsection{Transport network and travel demand}

The transport network is represented by a graph $\mathbf{G}(\mathbf{N}, \mathbf{A})$, where $\mathbf{N}(\mathbf{N}=\{1,2, \ldots, n\})$ is the set of nodes and $\mathbf{A}(\mathbf{A}=\{\mathrm{j}: \mathrm{j}=(\mathrm{h}, \mathrm{l}) ; \mathrm{h}, \mathrm{l} \in \mathbf{N})\})$ is the set of links. Besides, it is defined the set $\mathbf{C} \subset \mathbf{N}$ of customers including the depot $d$. Each element $r \in \mathbf{C}$ is characterized by a quantity $q_{r}$ (greater than 0) of freight to deliver, a time window $\left[o t_{r} c t_{r}\right]$ and a service time $s t_{r}$. The 


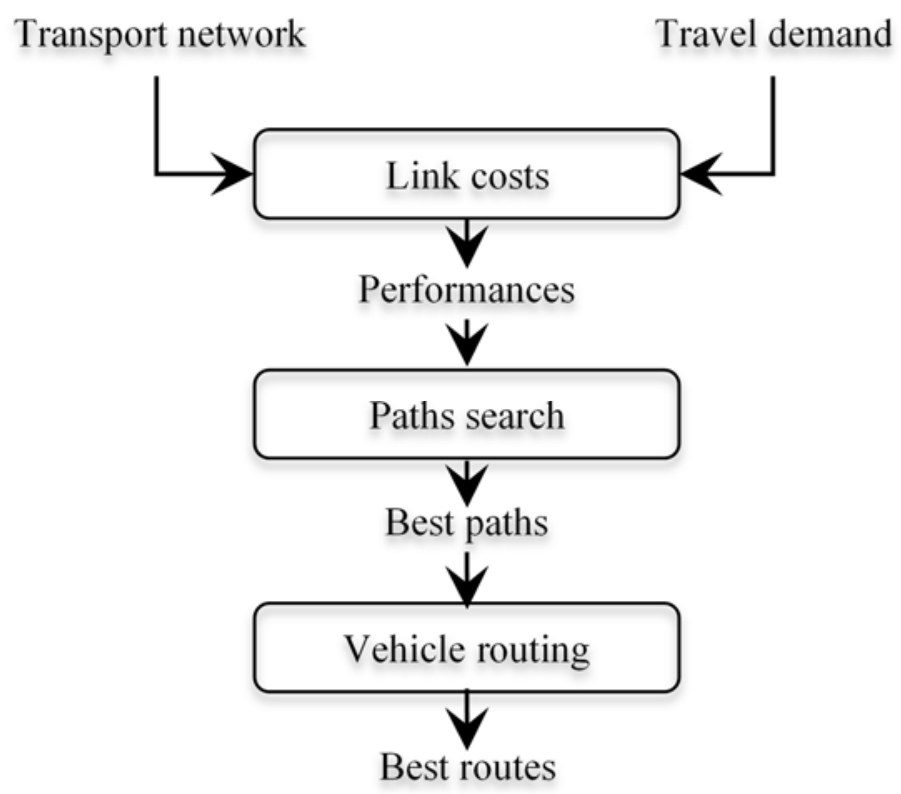

Forecast

Simulation

Optimization

Figure 1: Adopted method.

depot quantity and service time are assumed equal to zero and is not considered the time window constraint. For each couple $r$ and $s$ of elements belonging to the set $\mathbf{C}$ it is defined a cost, as reported is Section 2.3. To evaluate the performances of the transport network, we have to consider the interactions between different categories of vehicles. Particularly, the travel demand for passengers and freight is considered to evaluate the traffic flow and link cost for each element of the network, as explained in Section 2.2.

\subsection{Link cost and performances}

The reliable travel cost $\hat{c}_{m j}$ on a link $j$ in a time slice $m$ is defined as a function $\varphi(\cdot)$ depending on the average link cost $\bar{c}_{m j}$, the cost variance $\sigma_{m j}$, and the traffic flow $f_{m j}$ :

$$
\hat{c}_{m j}=\varphi\left(\bar{c}_{m j}, \sigma_{m j}, f_{m j}\right) .
$$

With this definition, the reliable cost $\hat{c}_{m j}$ for a link $\mathrm{j}$ is, in general, different for each time slice, as reported in Fig. 2.

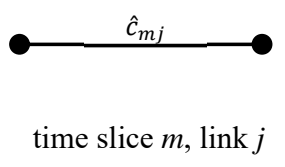

\begin{tabular}{|c|c|c|c|c|}
\cline { 2 - 5 } \multicolumn{1}{c|}{} & \multicolumn{4}{c|}{ Time slice } \\
\hline Link & 1 & $\ldots$ & $m$ &.. \\
\hline 1 & & & & \\
\hline$\ldots$ & & & & \\
\hline$j$ & & & $\hat{c}_{m j}$ & \\
\hline$\ldots$ & & & & \\
\hline
\end{tabular}

Figure 2: Link cost in relation to links and time slices. 


\subsection{Paths search and best path}

The path cost is, in general, defined summing (additive cost) the cost of links belonging to the path. Also non additive cost can be considered, with an extension of the model reported in this section. For the evaluation of the additive cost, the link-path incidence matrix is considered. Since the link cost depend also on the time slice $m$, this approach is modified in order to make the path cost dependent on the time slice:

$$
g_{k(r, s)}=\sum_{j} \delta_{k(r, s) m j} \times \varphi\left(\hat{c}_{m j}\right)
$$

where:

$\delta_{\mathrm{k}(\mathrm{r}, \mathrm{s}) \mathrm{mj}}$ is a binary variable equal to 1 if the link $j$ belongs to the path $k(r, s)$ from origin $r$ to destination $s$ in the time slice $m, 0$ otherwise;

$\varphi\left(\hat{c}_{m j}\right)$ is a function of the reliable link cost.

Fig. 3 shows this relation.

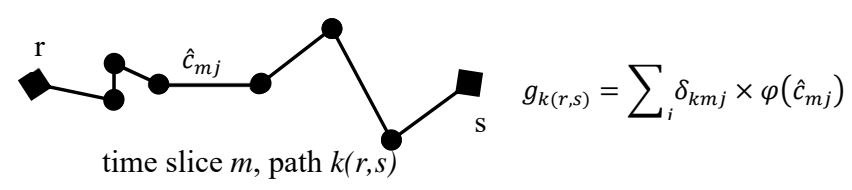

Figure 3: Path cost.

\subsection{Vehicle routing and best route}

The problem is formulated in order to minimize the total cost of the fleet tour. Assuming a fleet of homogenous vehicles (e.g. same load capacity, same battery capacity, ...), the formulation of the problem is reported in eqn (3), where the objective function is the sum of the costs related to all tours needed to perform the delivery service (a tour for each vehicle $v)$. The cost is represented by $g_{k(r, s)}$ (defined in previous section), the problem (binary) variable is represented by $X_{v k(r, s)}$. Eqns (4)-(7) are the problem constraints: constraint (4) establish that an user $s$ can be reached only once, constraints (5) and (6) impose that the vehicles start and come back to the depot $d$, constraint (7) is on the load capacity of the vehicles, constraint (8) is related with the max length of the tour, in relation to the range of the vehicle (depending on the battery capacity). This specific constraint is named electric constraints.

Finally, the constraint (9) defines the value that can be assumed by the design variable.

The model, including the objective function, the control variables and the constraints, is:

$$
\text { minimize } \Phi(\boldsymbol{X})=\sum_{v} \sum_{k} g_{k(r, s)} X_{v k(r, s)},
$$

subject to:

$$
\begin{gathered}
\sum_{v} \sum_{s} X_{v k(r, s)}=1 \quad \forall i \in C ; i, j \neq d ; i \neq j \\
\sum_{v} \sum_{s} X_{v k(d, s)}=u \\
\sum_{v} \sum_{s} X_{v k(s, d)}=u \\
\sum_{r} \sum_{s} q_{s} \cdot X_{v k(r, s)} \leq b_{v} \quad \forall v
\end{gathered}
$$




$$
\begin{gathered}
L_{\text {max }} \leq \alpha \cdot R A N_{v} \quad \forall v, \\
X_{v k(r, s)} \in\{0,1\},
\end{gathered}
$$

where:

$u$ is the number of vehicles;

$b_{v}$ is the load capacity;

$q_{s}$ is the freight quantity;

$L_{\text {max }}$ the max length of a tour;

$R A N_{v}$ is the vehicle range;

$\alpha$ is a parameter less than 1 to avoid the total discharge of the battery [44].

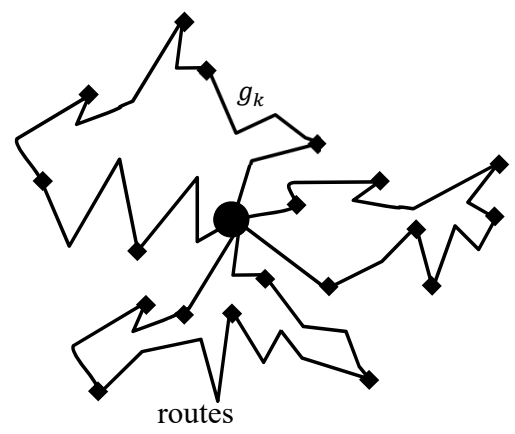

minimize $\Phi(\boldsymbol{X})=\sum \sum g_{k(r, s)} X_{v k(r, s)}$

Figure 4: Vehicle routing.

\section{NUMERIC RESULTS}

In this section some results obtained in recent publications in three case studies are reported (Table 1).

\section{$3.1 \mathrm{I}$}

The first experience [45] is relative to an experiment developed in Catania (Italy). In this experiment, some vehicles delivering dairy products are equipped with a GPS tracker in order to detect the vehicles tour and stops. The surveyed data allows to obtain: (i) values related to the travel time related to a set of links; and (ii) the sequence of users served by each vehicle. Considering the surveyed data on travel time, a link cost function was specified and calibrated for three categories of links. Considering the data on the sequence of users, a comparison between observed and optimized tours (by a genetic algorithm) was performed. The results demonstrate that the optimization procedure can reduce the observed time by up to $16 \%$.

\subsection{II.}

The second experience [46] is relative to an experiment developed in Villa San Giovanni (Italy). The proposed approach is based on the network fundamental diagram (NFD) at two levels (link and area). A reliable link travel times function is proposed by considering a congestion term (generalized cost) and a reliability term (depends on the NFD of the link and on the NFD of the area where the link is located). In the experiment, two objective functions are defined for VRP: the first one considers only the generalized cost, the latter the reliable 
link travel time. The results demonstrate that the approach with reliable link travel time can improve the optimization by up to the $5 \%$.

\subsection{III.}

The third experience [47], [48] is relative to an experiment developed in Roccella (Italy). The experiment is relative to the backward area of the Port. Electric vehicles are considered for the routing. The energy for vehicle recharge will be produced by the sea and the transport service will be with zero emission in the wall chain Well-To-Tank/Tank-To-Wheel. Data considered for the models' calibration are obtained from floating car data.

Routing services are designed in different mobility scenarios. Three objective functions (eqn (3)) are considered in the optimization: minimum energy; minimum travel time; minimum travel distance. In the objective function, only one objective is considered (monocriterion approach) among those reprinted. Furthermore, the energy consumption is evaluated considering the equations of the mechanics of locomotion, considering also the recoveries of energy in the case of the electric vehicle. Therefore, the energy consumed and the travel time do not have a high degree of correlation. With the criteria of minimum travel time (III.a), the travel time reduction is about $22 \%$ respect the values obtained with the criteria of minimum energy consumption. With the criteria of minimum energy consumption (III.b), the energy is reduced about $29 \%$ respect the values obtained with the criteria of minimum travel time.

These analyses become relevant when planning the number of paving stones to be used as energy savings require longer travel times and therefore a greater number of available vehicles and related costs.

Table 1: Comparison of the case studies.

\begin{tabular}{|c|c|c|c|c|}
\hline Case study & I. & II. & \multicolumn{2}{|l|}{ III. } \\
\hline Urban (U), Extra-urban (E) & $\mathrm{U}$ and $\mathrm{E}$ & $\mathrm{U}$ & \multicolumn{2}{|c|}{$\mathrm{U}$ and $\mathrm{E}$} \\
\hline Floating car data & Yes (Small) & No & \multicolumn{2}{|c|}{ Yes (Big) } \\
\hline $\begin{array}{l}\text { a. Estimation of reliable link travel } \\
\text { time }\end{array}$ & Yes & $\begin{array}{c}\text { No } \\
\text { (simulated) }\end{array}$ & \multicolumn{2}{|l|}{ Yes } \\
\hline b. Generation and choice of best path & Yes & Yes & \multicolumn{2}{|c|}{ Yes } \\
\hline c. Evaluation and choice of best route & Yes & Yes & \multirow{2}{*}{\multicolumn{2}{|c|}{$\begin{array}{c}\text { Yes } \\
\text { Traditional and Pure } \\
\text { Electric }\end{array}$}} \\
\hline d. Typology of vehicles & Traditional & Traditional & & \\
\hline Criterion for the optimum & Travel time & Travel time & $\begin{array}{l}\text { III.a Travel } \\
\text { time }\end{array}$ & $\begin{array}{l}\text { III.b } \\
\text { Energy }\end{array}$ \\
\hline Reference scenario & Current & Current & III.b & III.a \\
\hline Travel time in optimal scenario & $-16 \%$ & $-5 \%$ & $-22 \%$ & - \\
\hline Energy in optimal scenario & - & - & - & $-29 \%$ \\
\hline
\end{tabular}

\section{CONCLUSIONS}

In this paper, the problem of optimizing vehicle routing has been studied. The problem is relevant for the planning of services and the ex-ante evaluation of the effects deriving from interventions. The problem has been faced considering the use of electric vehicles that require particular autonomy constraints but allow the planning and realization of sustainable services. 
The problem has been formulated considering three main aspects: the generalized cost on the links of the transport network and the relative reliability; the route cost between each pair of nodes to be visited for the taking and delivery of the freight; the best sequences of the nodes to visit.

Some case studies have been reported where it is noted that the optimization of services produces benefits of travel times varying between $5 \%$ and $22 \%$. In terms of the use of electric vehicles, the optimization with respect to energy implies an increase in travel times; in percentage terms, the two quantities (energy reduction and increase in travel time) are quite comparable ( $29 \%$ and $22 \%)$.

The reported and commented results refer only to case studies. In the future these results will have to be confirmed and compared in other case studies to validate the goodness of the reported methodology.

\section{ACKNOWLEDGEMENT}

This research is partially supported by the project GRE.ENE.LOG., funded by Calabria Region via POR CALABRIA FESR - FSE 2014-2020, Prog. 2894, Prot. SIAR 52115, date $17 / 02 / 2017$.

\section{REFERENCES}

[1] Comi, A., Donnelly, R. \& Russo, F., Urban freight models. Modelling Freight Transport, eds L. Tavasszy \& G. de Jong, Elsevier, pp. 163-200, 2013.

[2] Russo, F. \& Rindone, C., Container maritime transport on an international scale: Data envelopment analysis for transhipment port. WIT Transactions on Ecology and the Environment, vol. 150, WIT Press: Southampton and Boston, pp. 831-846, 2011.

[3] Russo, F., Musolino, G. \& Assumma, V., Competition between ro-ro and lo-lo services in short sea shipping market: The case of Mediterranean countries. Research in Transportation Business and Management, 19, pp. 27-33, 2016.

[4] Russo, F. \& Musolino, G.A., Unifying modelling framework to simulate the spatial economic transport interaction process at urban and national scales. Journal of Transport Geography, 24, pp. 189-197, 2012.

[5] Cirianni, F., Panuccio, P. \& Rindone, C., A comparison of urban planning systems between the UK and Italy: Commercial development and city logistic plan. WIT Transactions on the Built Environment, vol. 130, WIT Press: Southampton and Boston, pp. 785-797, 2013.

[6] Polimeni, A. \& Vitetta, A., Optimizing wait time at nodes in time-dependent networks: Cost functions and applications. Journal of Optimization Theory and Applications, 156(3), pp. 805-818, 2013.

[7] Russo, F., Rindone, C. \& Panuccio, P., European plans for the smart city: From theories and rules to logistics test case. European Planning Studies, 24(9), pp. 17091726, 2016.

[8] Russo, F., Vitetta, A. \& Polimeni, A., From single path to vehicle routing: The retailer delivery approach. Procedia - Social and Behavioral Sciences, 2(3), pp. 6378-6386, 2010.

[9] Musolino, G., Polimeni, A. \& Vitetta, A., Freight vehicle routing with reliable link travel times: A method based on network fundamental diagram. Transportation Letters 10(3), pp. 159-171, 2018.

[10] Comi, A., Buttarazzi, B. \& Schiraldi, M., Smart urban freight transport: tools for planning and optimising delivery operations. Simulation Modelling Practice and Theory, 88, pp. 48-61, 2018. 
[11] Musolino, G., Rindone, C., Polimeni, A. \& Vitetta A., Planning urban distribution center location with variable restocking demand scenarios: General methodology and testing in a medium-size town. Transport Policy, 80, pp. 157-166, 2019.

[12] Wardrop, J.P., Some theoretical aspects of road traffic research. Proceedings of the Institute of Civil Engineers, Part II, 1, pp. 325-378, 1952.

[13] Cascetta, E., Transportation Systems Analysis: Models and Applications, Springer, 2009.

[14] Marcianò, F.A., Musolino, G. \& Vitetta, A., Signal setting design on a road network: Application of a system of models in evacuation conditions. WIT Transactions on Information and Communication Technologies, vol. 43, WIT Press: Southampton and Boston, Part I, pp. PI443-PI454, 2010.

[15] Hoose, N., Computer Image Processing in Traffic Engineering, Research Studies Press, 1991.

[16] Torday, A. \& Dumont, A.G., Probe vehicle based travel time estimation in urban networks. Proceedings of TRISTAN V, 2004.

[17] Russo F. \& Vitetta, A., Reverse assignment: Calibrating link cost functions and updating demand from traffic counts and time measurements. Inverse Problems in Science and Engineering, 19(7), pp. 921-950, 2011.

[18] Ben-Akiva, M.E., Bergman, M.J., Daly, A.J. \& Ramaswamy, R., Modelling interurban route choice behaviour. Proceedings of the 9th International Symposium on Transportation and Traffic Theory, VNU Science Press, pp. 299-330, 1984.

[19] Morikawa, T., A hybrid probabilistic choice set model with compensatory and noncompensatory rules. Proceedings of the 7th WCTR, Sydney, Australia, 1996.

[20] De Maio, M.L. \& Vitetta, A., Route choice on road transport system: A fuzzy approach. Journal of Intelligent and Fuzzy Systems, 28(5), pp. 2015-2027, 2015.

[21] Vitetta, A., A quantum utility model for route choice in transport systems. Travel Behaviour and Society, 3, pp. 29-37, 2016.

[22] Fisher, M.L., Optimal solution of vehicle routing problems using minimum k-trees. Operations Research, 42(4), pp. 626-642, 1994.

[23] Fisher, M.L., Jörnsten, K.O. \& Madsen, O.B.G., Vehicle routing with time windows: Two optimization algorithms. Operations Research, 45(3), pp. 488-492, 1997.

[24] Kohl, N. \& Madsen, O.B.G., 2-Path cuts for the vehicle routing problem with time windows. Transportation Science, 1, pp. 101-116, 1999.

[25] Toth, P. \& Vigo, D., Models, relaxations and exact approaches for the capacitated vehicle routing problem. Discrete Applied Mathematics, 123, pp. 487-512, 2002.

[26] Chabrier, A., Vehicle routing problem with elementary shortest path based column generation. Computer and Operations Research, 33, pp. 2972-2990, 2006.

[27] Baldacci, R., Christofides, N. \& Mingozzi, A., An exact algorithm for the vehicle routing problem based on the set partitioning formulation with additional cuts. Mathematical Programming, 115(2), pp. 351-385, 2008.

[28] Qureshi, A.G., Taniguchi, E. \& Yamada, T., An exact solution approach for vehicle routing and scheduling problems with soft time windows. Transportation Research Part E, 45, pp. 960-977, 2009.

[29] Azi, N., Gendreau, M. \& Potvin, J.Y., An exact algorithm for a vehicle routing with time windows and multiple routes. European Journal of Operational Research, 178, pp. 755-766, 2010.

[30] Larrain, H., Coelho, L.C., Archetti, C. \& Speranza, M.G., Exact solution methods for the multi-period vehicle routing problem with due dates. Computers and Operations Research, 110, pp. 148-158, 2019. 
[31] Salavati-Khoshghalb, M., Gendreau, M., Jabali, O. \& Rei, W., An exact algorithm to solve the vehicle routing problem with stochastic demands under an optimal restocking policy. European Journal of Operational Research, 273(1), pp. 175-189, 2019.

[32] Badeau, P., Guertin, F., Gendreau, M., Potvin, J.Y. \& Taillard, E., A parallel tabu search heuristic for the vehicle routing problem with time windows. Transportation Research C, 5(2), pp. 109-122, 1997.

[33] Jones, D.F., Mirrazavi, S.K. \& Tamiz, M., Multi-objective meta-heuristics: An overview of the current state of the art. European Journal of Operational Research, 137, pp. 1-9, 2002.

[34] Montemanni, R., Gambardella, L.M., Rizzoli, A.E. \& Donati, A.V., Ant colony system for a dynamic vehicle routing problem. Journal of Combinatorial Optimization, pp. 327-343, 2005.

[35] Laporte, G., What you Should Know about the Vehicle Routing Problem, Les-Cahiersdu-GERAD, 2007.

[36] Bin, Y., Zhong-Zhen, Y. \& Baozhen, Y., An improved ant colony optimization for vehicle routing problem. European Journal of Operational Research, 196, pp. 171176, 2009.

[37] Repoussis, P.P. \& Tarantilis, C.D., Solving the fleet size and mix vehicle routing problem with time windows via adaptive memory programming. Transportation Research Part C: Emerging Technologies, 18(5), pp. 695-712, 2010.

[38] Zachariadis, E.E. \& Kiranoudis, C.T., An open vehicle routing problem metaheuristic for examining wide solution neighborhoods. Computers and Operations Research, 37, pp. 712-723, 2010.

[39] Syrichas, A. \& Crispin, A., Large-scale vehicle routing problems: Quantum annealing, tunings and results. Computers and Operations Research, 87, pp. 52-62, 2017.

[40] Pelletier, S., Jabali, O. \& Laporte, G., The electric vehicle routing problem with energy consumption uncertainty. Transportation Research Part B: Methodological, 126, pp. 225-255, 2019.

[41] Ehsani, M., Gao, Y., Gay, S.E. \& Emadi, A., Modern Electric, Hybrid Electric, and Fuel Cell Vehicles: Fundamentals, Theory, and Design, CRC Press, 2005.

[42] Chan, C.C., The state of the art of electric, hybrid, and fuel cell vehicles. Proceedings of the IEEE 2007, 95(4), pp. 704-718, 2007.

[43] Shaukata, N. et al., A survey on electric vehicle transportation within smart grid system. Renewable and Sustainable Energy Reviews, 81, pp. 1329-1349, 2018.

[44] Franke, T. \& Krems, J.F. Interacting with limited mobility resources: Psychological range levels in electric vehicle use. Transportation Research Part A, 48, pp. 109-122, 2013.

[45] Polimeni, A. \& Vitetta, A., Vehicle routing in urban areas: An optimal approach with cost function calibration. Transportmetrica B: Transport Dynamics, 2(1), pp. 1-19, 2014.

[46] Musolino, G., Polimeni, A. \& Vitetta, A., Freight vehicle routing with reliable link travel times: A method based on network fundamental diagram. Transportation Letters, 10(3), pp. 159-171, 2018.

[47] Croce, A.I., Musolino, G., Rindone, C. \& Vitetta, A., Transport system models and big data: Zoning and graph building with traditional surveys. FCD and GIS. ISPRS Int. J. Geo-Inf., 8, p. 187, 2019.

[48] Croce, A., Musolino, G., Rindone, C. \& Vitetta, A., From GREen ENErgy to green LOGistic: A joint analysis of energy, accessibility and mobility. Advances in Modelling and Analysis A, 55(3), pp. 121-127, 2018. 